Portland State University

PDXScholar

\title{
Experiences of Shame, Exclusion, \& Appropriation in Mindfulness-based Wellness Culture
}

Charlotte Grace Starling

Portland State University

Follow this and additional works at: https://pdxscholar.library.pdx.edu/honorstheses

Part of the Critical and Cultural Studies Commons, and the Mental and Social Health Commons Let us know how access to this document benefits you.

\section{Recommended Citation}

Starling, Charlotte Grace, "Experiences of Shame, Exclusion, \& Appropriation in Mindfulness-based Wellness Culture" (2021). University Honors Theses. Paper 968.

https://doi.org/10.15760/honors.992

This Thesis is brought to you for free and open access. It has been accepted for inclusion in University Honors Theses by an authorized administrator of PDXScholar. Please contact us if we can make this document more accessible: pdxscholar@pdx.edu. 
Experiences of Shame, Exclusion, \& Appropriation in Mindfulness-based Wellness

\title{
Culture
}

\author{
Charlotte Starling \\ University Honors College, Portland State University \\ Undergraduate Thesis \\ Advised by Claire Wheeler MD, Ph.D. \\ February 26th, 2021
}




\begin{abstract}
Yoga, meditation, and other mindfulness practices provide numerous benefits both physical and mental health to their practitioners (Shapiro et al., 2016). There is less research exploring the role mindfulness-based wellness programs and practices fit within the cultural environment of the United States and how the mindfulness movement influences wellness culture and practices. These practices and spaces have been accused of harming folks who don't fit the dominant social narrative of thin, white, upper-middle-class participants. This paper aims to explore how the United State's commodification of mindfulness practices contributes to experiences of shame, exclusion, and appropriation in wellness culture. This is done by a literature review of the existing academic research that relates to U.S. mindfulness-based wellness culture while also analyzing the existing social commentary and media beyond peer-reviewed academic work. Within this paper the author identifies four major aspects of focus- the commodification of mindfulness culture itself, and the corporate mindfulness practices, cultural appropriation, and racism that happen in response. Reconciliation is needed between mindfulness teachings, practitioners, and participants of all backgrounds for mindfulness-based wellness practices and culture to be accessible and inclusive to all.
\end{abstract}




\section{Introduction}

As social creatures, people need relationships and social skills that nurture us while fostering kindness, genuine connection, and peace with others. Our social well-being depends on the relationships people have not only with others, but on the social environment that people exist within. The World Health Organization defines health as "a state of complete physical, mental and social well-being and not merely the absence of disease or infirmity" (Otorkpa, 2019). Well-being is a human birthright, and mindfulness practices such as yoga and meditation can be an excellent way to promote physical and mental health (Shapiro et al., 2016). However, there are still questions about how mindfulness practices can adequately foster social well-being for all who choose to practice.

\section{My research question/goals}

It has been established that yoga, meditation, and other mindfulness practices provide numerous benefits both physical and mental health to their practitioners (Shapiro et al., 2016). However, there is less research exploring the role mindfulness-based wellness programs and practices fit within the cultural environment of the United States and how the mindfulness movement influences wellness culture and practices. These practices and spaces have been accused of harming folks who don't fit the dominant social narrative of thin, white, upper-middle-class participants. This paper aims to explore how the United State's commodification of mindfulness practices contributes to experiences of shame, exclusion, and appropriation in wellness culture.

For the purpose of this thesis, mindfulness-based wellness (MBW) practices are defined as yoga and meditation. Mindfulness-based wellness spaces are defined as studios/classes, retreats, religious buildings, storefronts, media, and any other place virtual or physical that are centered around the practices mentioned above. Wellness culture will be defined as the social dynamics, values, attitudes, and opinions embodied in mindfulness-based wellness practices, 
spaces, and practitioners. This thesis will be limited to analyzing the United States' wellness culture.

\section{Methods}

In this thesis, I will be conducting a literature review of the existing academic research that relates to U.S. mindfulness-based wellness culture at a broader level and the individual level. To supplement this and ensure that my work is inclusive of the diverse perspectives it wishes to explore I will also be analyzing the existing social commentary and media beyond peer-reviewed academic work. This is to acknowledge the potential echo chamber of academia and its tendency to uplift white-centered narratives. By including news articles from sources such as The Guardian and The Atlantic, blog posts and articles that feature personal, lived experiences of individuals, and works such as the book McMindfulness (Purser, 2019), this thesis will provide an in-depth, qualitative review of U.S. wellness culture and associated experiences of shame, exclusion and appropriation.

\section{Background}

Benefits of mindfulness \& movement-based practices in the research literature

The author of this paper by no means is trying to discredit the beneficial uses of meditation and yoga. The goal of this paper is not to critique traditional mindfulness-based wellness practices or movement-based practices. Rather, this paper aims to critically examine how these practices have been packaged and represented in U.S. society. My work's focus is on how America has westernized these practices, and critiques are based solely on the commodified versions of yoga and meditation that are being mass-marketed within the United States.

There are many types of meditations. A typical mindfulness meditation has two main components, attention, and acceptance (Creswell \& Khoury, 2019). In a mindfulness meditation 
practice, the attention component is about focusing your attention on the current moment. Attention is about being aware of you and everything around you (physically and mentally). This is most often done by holding one posture and examining your breathing, emotions and thoughts. The acceptance part is about observing your thoughts, emotions, and feelings neutrally, without assessing them or passing judgement. In most meditation practices, the participant is supposed to not react to those emotions and thoughts but rather let them go. Acknowledge those are thoughts and feelings you have, but not dive further into them. This practice is supposed to help nurture a calmer, less reactive mind. A mindfulness meditation can last anywhere from 3 to 5 minutes to over an hour, depending on the individual.

Value has been placed in the mindfulness and movement-based practices of yoga and meditation for thousands of years. Steeped in traditional wisdom, billions of people around the world historically and currently use yoga and meditation to improve their physical and mental health. It would be a disservice to not acknowledge the widespread good that these practices continue to provide. Outside of the United States, medical practitioners have long prescribed yoga and/or meditation to their patients as ways of nurturing well-being. Academic and scientific research conducted outside of the United States on yoga and meditation has consistently identified and affirmed their positive efficacy. A few notable studies have seen beneficial results related to yoga, meditation, and mindfulness's impact on anxiety and stress (Bränström et al., 2011), Type 2 diabetes (Kumar et al., 2016), Coronary heart disease (Ray et al., 2014), and mental health (Chu, 2010).

The potential physical and mental health benefits for mindfulness and movement-based practices have been a growing source of interest for various United States-based academic and research communities (Shapiro \& Walsh, 2003). An ever-expanding body of research literature offers compelling evidence for the incorporation of these practices into day-to-day life for many reasons (Grossman et al., 2004). Practices such as mindfulness meditation or yoga have been shown to mitigate stress, trauma, illness, and injury (Keosaian et al., 2016; Schreiner \& 
Malcolm, 2008). They help treat a combination of physical and mental concerns while being cost-effective since they require few resources and can be taught in groups. Research has seen improvements related to anxiety, depression, stress, chronic pain, chronic illness, post-traumatic stress disorder, and more (Dutton et al., 2013; Keosaian et al., 2016; Saper et al., 2017; Streeter et al., 2012). One particularly well-studied area of interest is Mindfulness-Based Stress Reduction (MBSR), a secular, evidence-based mindfulness program founded by Dr. Jon Kabat-Zin (Abercrombie et al., 2007; Dutton et al., 2013; Roth \& Robbins, 2004).

Demographics of who occupies mindfulness-based wellness spaces \& critiques of social dynamics

As mindfulness-based wellness practices shifted in the U.S., the culture around them adapted to include new demographics, changing the social dynamics as well. Practices such as yoga and meditation were once almost exclusively associated with Eastern religions. Now, these practices are widely popularized and key pillars of the fitness/health industry. Most likely when you ask someone about yoga, they would describe a skinny, white woman in leggings at a studio. This is not necessarily a wrong assumption, the dominant demographic for yoga is upper-middle-class, educated, white women with low BMls (Park et al., 2015). For meditation, white, older women also made up a large body of those who practice. When the United State's dominant demographic in these practices is skinny, upper-class, white women it does raise potential concerns (Quilty et al., 2013). If this is who represents the wellness industry, is there acceptance and space for those who differ from this narrative? On paper, industry leaders in yoga, meditation, and other mindfulness-based wellness practices say yes, and while the practices themselves do seem to be inclusive, the cultural environments in the U.S. are increasingly being criticized for their social dynamics lacking openness and inclusivity (Purser, 2019). There are a variety of stand-alone concerns including religious appropriation, body image/fat shaming, racism, classism, ableism, and heterosexism that have been raised both in and beyond the academic literature but there is little cohesive research on the cultural and 
social dynamics of mindfulness-based wellness practices in the U.S. and their impacts on individuals (Bruce, 2019; Danis, 2018; Miller, 2016; Rosenfeld, 2016; Smith \& Atencio, 2017).

\section{The Commodification of Mindfulness-based Wellness Practices}

"Yoga's journey from ancient spiritual practice to big business and premium lifestyle" is abhorrent and that "a practice originally intended as a vehicle for transcending the ego has become a seemingly vanity-driven pursuit" underlines the ethical and spiritual dilemmas behind the phenomenal growth of yoga as spiritual, fitness and lifestyle pursuit in Western contexts and how it has seemingly transcended beyond its humble genesis focused on spirituality, universal access, and egalitarianism. (Bowers \& Cheer, 2017, p. 211) \& (Gregiore, 2013)

Yoga was introduced to the United States around 1893, but public perception and practice of yoga have changed drastically since then (Quilty et al., 2013). When yoga gained popularity and social acceptance in the United States, it adapted from being closely related to spiritual/religious practices to a more secular, health, and wellness orientation (Delaney, 2017).

As these practices grew in popularity in the United States, whole industries were created around them. This commodification of yoga culture leads us to today where yoga studios, equipment, clothing, retreats, magazines, and other forms of media make yoga an over 15 billion dollar industry (as of 2016), (Delaney, 2017; Segran et al., 2015).

Yoga in the U.S. has become a lifestyle - its commodification is accompanied by U.S. societal standards. This is embodied by the overpriced athleisure of industry star Lululemon's $\$ 100$ yoga pants. Businesses that have situated themselves in the wellness sphere go to great lengths to emphasize the importance of health, inclusivity, being the best version of yourself, etc without actually following through on these claims. An obvious example of this is size inclusivity. Up until September of 2020, Lululemon's yoga pants were not available past a size 14; the average size of an American woman is between a size 16 to 18 (Hall, 2015). Six of the brand's styles are now available in up to size 20. Athleta on their website boasts that "We Celebrate Bodies. Everything changes when you deeply understand the female body and insist on enhancing every curve" (Athleta, n.d.). An interesting claim for a company that just announced 
(January 2021) they will be expanding their sizes up to 3X for their Spring 2021 collection. Even new names like Outdoor Voices, who gained their social media popularity for being trendy and inclusive, fall short; they offer leggings only up to size $\mathrm{XL}$.

How brands, studios, and media interact with one another allows them to continue to assert their inclusiveness and wokeness. The lack of popular yoga clothing with inclusive sizing is reflected in studios that are comprised mainly of small, white women. Popular media whether magazines, blogs/websites, or Instagram/Facebook often highlight the most successful and appealing of these studios and instructors- again mainly small, white women. This feedback loop is how influencers such as Kathryn Budig can become the face of the body positivity movement in yoga (Miller, 2016). Budig is a renowned American yoga teacher, author, and frequent face/contributor to yoga magazines. She is also a tall, slim white woman with blonde hair and blue eyes. The body positivity movement's purpose is to challenge how society views the physical body, and advocates for acceptance of all bodies (i.e. size, race, gender, or physical ability). When a movement meant to highlight the bodies society normally minimizes is given a spokesperson whose physical attributes are overrepresented in wellness culture, it loses some of its power. Many activists in the movement ask why this seemingly perfect opportunity to uplift marginalized yogis was instead given to an already successful white woman (Bondy, 2014).

"We are not seeing or talking about who is truly pushed to the margins... the people who are underserved here and ignored are the truly larger bodied practitioners, people of color, disabled bodied, transgender bodied." (Bondy, 2014)

Others point out how the industry making Budig the focal point of the conversation has appropriated the movement itself, taking away the very point the body positivity movement is striving to make. The body positivity movement is not just a matter of individual self-acceptance, but also of critically engaging the social and cultural systems that decide which bodies are worth celebrating. 
"Stories like hers (Kathryn Budig) speak to a common suffering of body-shaming, self-doubt, and self-hate experienced by many in our society, including those who are white, size 4, young, able-bodied, and cisgender. Rather, critics seek to acknowledge the systemic overrepresentation of voices, bodies, and bodily experiences like hers, which generally receive more attention, applause, acceptance, and support. They draw attention to the role the yoga industrial complex has played, with Budig's complicity, in appropriating body positivity in ways that don't accurately reflect the diversity and complexity of yoga or yogis: Budig's articles and talks continue a tradition of privileging particular bodies and marginalizing others." (Miller, 2016, p. 6-7)

There is concern with the 'gurus' who are the face of this newfound form of mindfulness-based wellness culture and their motives. It's no easy task to stay true to genuine wellness for the people in an industry where massive profits and fame can be achieved for those at the top. Bikram Choudhury, the founder of Bikram Yoga (more commonly known as hot yoga), is an excellent example. Bikram's 90 -minute yoga sessions feature 26 poses in studios that maintain humid $105^{\circ} \mathrm{F}$ temperatures. Bikram's hot yoga has become a popular, hip alternative to typical yoga classes and has brought Bikram a formidable amount of success. In his prime, Bikram's personal net worth was an estimated $\$ 75$ million. Training to become a Bikram Yoga instructor alone cost over $\$ 10,000$ to attend (Farrell, 2009). With his accumulation of wealth and fame came a brashness in character as well. In an interview with Brigid Delaney of The Guardian, Bikram told her she "needed to do some Bikram. You [Brigid] are overweight" (Delaney, 2017). Many now associate Bikram with the multitude of rape and sexual assault allegations and charges made against him since the early 2010s (Godwin, 2017). In 2017, Minakshi Jafa-Bodden was awarded $\$ 6.8$ million in damages by a Los Angeles jury in her suit against Bikram for unlawful dismissal and sexual harassment. In response, Bikram fled the United States while denying all allegations aggressively - "Why do I have to harass women? People spend \$1 million for one drop of my sperm. Are you that dumb to believe those trash?" Even many of the purported health benefits of Bikram/hot yoga have been called into question. Hot yoga's $105^{\circ}$, fast-paced studios claim benefits such as increased calorie loss, and flexibility. 
However, the American Council of Exercise (ACE) has cited potential health concerns of overheating, dehydration, and overstretching (Hot Yoga, 2019).

The case study of Bikram Choudhury begs the question- is it possible to start with honest intentions but end up corrupted by an industry that only loosely hides its true values of wealth, vanity, and social control? On a larger scale, can the conditions of U.S. mindfulness-based wellness culture create 'gurus' that are more than shallow representations, and ultimately a betrayal of the word itself?

\section{Corporate Mindfulness or McMindfulness}

"When facing increasing demands or precariousness, for instance, corporate mindfulness conditions practitioners to favor strategies of adaptation and adjustment, allowing them to function better in the world, rather than work to change it." (Walsh, 2018, p.113)

Corporate mindfulness, often referred to as McMindfulness, is a term that was coined by Buddhist teacher Miles Neale as "spiritual practices that provide immediate nutrition but no long-term sustenance (Neale, 2011)." Scholar Ronald Purser is associated with the popularization of the term due to his piece in the Huffington Post, "Beyond Mindfulness" (Purser \& Loy, 2013) and his book McMindfulness (Purser, 2019). Purser asserts that "void of a moral compass or ethical commitments, unmoored from a vision of social good, the commodification of mindfulness keeps it anchored in the ethos of the market."(Purser, 2019, p. 17). Critical scholars of corporate mindfulness often point out their concern is not with the popularization of mindfulness but rather with the way and type of mindfulness being marketed and adapted in the United States. Corporate mindfulness is often promoted as a way to help maintain a "healthy" work-life balance, and increase productivity while reducing stress and anxiety (Kristensen, 2018).

In an ever-busy, rapidly developing world, where most people are balancing a $40+$ hour work week, household duties, caring for children, and a social life, corporate mindfulness has 
quickly gained traction. However, the zen promised by the corporate mindfulness movement may have a dark side to it. Many critics have pointed out that commodified mindfulness practices offer little meaningful, lasting change, and are just a guise of caring for the individual worker while looking to better the company's bottom line (Purser, 2019). One happiness guru, Tony Hsieh (also CEO of Zappos) argues that businesses benefit from nurturing employee happiness and should hire Chief Happiness Officers. However, he also recommends these happiness officers should lay off the employees who are among the $10 \%$ least enthusiastic, to "super-engage" the rest of their employees (Davies, 2015). Is the threat of being fired a good motivator to be a genuinely happy employee?

In this era of late-stage capitalism, job insecurity, financial well-being, unfair labor expectations, and employee burnout are becoming the norm (Bialik \& Fry, 2019). For Millennials, in comparison to Generation X and Baby Boomers, prosperity and high quality of life can feel like lofty goals. Corporate mindfulness was developed in response to these concerns, but as the name suggests, its priorities are situated on the corporate side of the issue and not the individuals. As a result, there are some questions on the efficacy, motivations, and ethicalness of this new wave of corporate mindfulness. Some scholars question if mindfulness can exist harmoniously within a neoliberal, capitalist society (Purser, 2019). They argue that the appropriation of mindfulness-based wellness practices furthers neoliberal capitalist agendas; robbing mindfulness of its ethical power, altering it from a call to action for social change into a tool for maintaining the capitalist status quo.

The structure and values of corporate mindfulness are rooted in neoliberal white supremacy (Purser, 2019). These experiences of shame, exclusion, and appropriation that thrive in U.S. mindfulness culture result in discriminatory acts including racism, classism, ableism, heterosexism, and fattism (Scherer \& Waistell, 2018). The experiences of exclusion and shame that this paper explores do not exist within a vacuum. It is impossible to truly address their impact without identifying their root causes, one of which is corporate mindfulness. 
The United States has taken mindfulness practices and commodified them as desired to better suit the economy's capitalistic needs and individualistic identities, leaving us with corporate mindfulness- a distorted, corrupt version of the original (Purser, 2018; Scherer \& Waistell, 2018).

"Mindfulness has also been criticized for pacifying people. For example, teaching employees ways to deal with stressful work environments, instead of changing the environment itself. Changing systemic oppression cannot be done through pacifying. Similarly, mindfulness in schools may aspire to teach children to be still and quiet instead of invoking curiosity and mindful presence. Historically, colonizers thought they were doing a good thing and took Indigenous children away from their families to teach them to be civilized, instead of the "savages" the colonizers believed they were. I see some parallels here. Mindfulness has been disseminated in the west by predominantly White people, and thereby has been introduced in ways that perpetuate colonizing values. I think it is important to think about how a practice of mindfulness can be used in a decolonized way, in a way that connects to traditional mindfulness practices that are in many cultures. (Street et al., 2020)"

The above quote is an excellent critique of corporate mindfulness. It raises valid concerns over the similarities of corporate mindfulness teachings and colonialist philosophies. There are many different ways of teaching of mindfulness, but within the United States, mindfulness training too often maintains values of pacification and conformity - whether its teachings are directed at children, employees, or even the military (Purser, 2019). The way corporate mindfulness ingrains these attitudes and behaviors into the American people often quells the belief that substantial change at the systemic level is possible. Corporate interests have creative control on the mindfulness-based wellness practices taught in their workplaces. This allows them to promote MBW that focus on techniques (such as breathing exercises) to cope with stressors rather than address them (Walsh, 2018). Some teachings focus solely on an individual, encouraging one to search within themselves to find a solution. This becomes problematic if the stressor is for example, a 45+ hour work week. Rather than MBW practices being the solution, the root problem of the stressor should be addressed. A company could hire more employees or lower individual workload while offering mindfulness-based wellness 
practices. Mindfulness-based wellness practices are not meant to maintain a status quo (Purser, 2019).

Some critics of capitalism note that corporate mindfulness works on the assumption that without an outside to colonize and appropriate, the system must learn to exploit the individual (Fisher, 2009; Walsh, 2018). Fisher talks of happiness and well-being as an economic resource in which mindfulness is used to manage people, to teach them how to adjust and adapt to an unhealthy environment rather than attempt to change it. Corporate mindfulness has established that stress is something caused by the individual and that the individual is responsible for managing it, regardless of the root cause (Walsh, 2018).

\section{Experiences of Cultural \& Religious Appropriation}

"Spirituality, while still a recognized ideal of practitioners, is secondary to the primary needs of self-improvement and career enhancement echoing the pursuits described in Elizabeth Gilbert's bestselling tome Eat, Pray, Love. (Bowers \& Cheer, 2017, p.215)"

Concepts of mindfulness can be seen throughout various cultural and religious backgrounds, and although the exact origins are unsure, both Hinduism and Buddhism have strong historical ties to mindfulness practices such as meditation and yoga (Lion's Roar, 2017). Gautama Buddha called mindfulness the "path to enlightenment" and "right mindfulness" is one of the primary teachings of the Eightfold Path of Buddhism (Goldstein, 2007). Yoga, a Sanskrit word, was first written in the Vedas, sacred Hindu texts which are some of the oldest religious texts in the world (Mark, 2020). Within Eastern religions, mindfulness practices such as yoga, meditation, and qigong are more than just physical acts - their spiritual teachings are central. This approach to mindfulness imparts the importance of ethical behavior, mind-body awareness, humility, and more. Individual benefits may be a clear, less reactive mind rather than increased productivity. Traditionally, the intention of mindfulness-based wellness practices is that the benefits of these practices go beyond the individual and reach all beings. When considering the westernization of mindfulness, many believe that it is not a practice to be taught exclusively tied 
to religion, but that it is absolutely necessary to include ethics and justice (Walsh, 2018).

Without ethics, the fear is that misappropriated mindfulness-based wellness practices result in confusion and conflicting messages, causing more harm than good (Monteiro et al., 2015).

"...When yoga is stripped of its cultural context, repackaged and sold as a white-American construction, it erases the variety of Indian indigenous traditions and compresses Indian identity into Hindu. The consequences of misunderstood cultural context are spiritual bypass and cultural appropriation, in which an entire culture is condensed into a practice intended for deep emotional recognition, yet used as medication..." (Bruce, 2019, p. 5-6)

There is a significant cause for concern when the "consequences of misunderstood cultural context [are] cultural appropriation" (Bruce, 2019). Cultural appropriation in U.S. mindfulness-based wellness spaces often results in the ostracization of individuals in which these practices hold religious/cultural significance. This is especially true when considering the scale that yoga and meditation practices have reached in the United States. It is important to emphasize both that the cultural appropriation within yoga and mediation is due to this fundamental misunderstanding of their teachings (and thus not intended to be hurtful) and does cause considerable harm to the communities and individuals in which these practices are culturally based. A reconciliation is needed between mindfulness teachings, practitioners, and participants of all backgrounds for these practices to honor their cultural, historical ties while existing in the Western world.

For people with cultural, religious ties to yoga and meditation, many feel outright excluded and hurt by the environment within the United States. Lakshmi, an Indian-American, shared her experiences with white yoga teachers who discussed how clothes in India didn't fit them because "people in India don't do yoga" while she applied henna to their bodies for a yoga fashion show (Nair, 2019). She also shares her experience of being harassed by a white yoga teacher after raising concerns with racial stereotyping that occurred at a yoga fundraiser. The woman in retaliation got Lakshmi fired from her volunteer position, attempted to sabotage 
Lakshmi at her place of work, and said she was "behaving like a terrorist from the Islamic State of Syria" (Nair, 2019).

\section{Experiences of Racism}

"Meanwhile, where has the mindfulness movement been? What has been done to directly confront systemic racism and white supremacy? A subtle indignation begs the question: should the present mindfulness movement be declared a failure and another pillar of white privilege and supremacy? (Street et al., 2020)"

There are many ways in which the mindfulness community has been complicit in acts of racism and white supremacy. Mindfulness-based wellness spaces have great potential to be a place for healing and be welcoming to people of color. Mindfulness practices can be used to reduce racial bias (Magee, 2015), working with public servants such as teachers, first responders, and police. Meditation can be used by white practitioners to examine how they perpetuate racism by looking inward at their privilege, biases, and stereotypes (Cohen, 2020). Mindfulness and meditation challenge a person to turn inward and investigate their thoughts, especially the ones that make them feel uncomfortable or shameful. Until a white person is willing to truly examine their role regarding racism, their attitude and actions cannot change. Meditation allows people to reflect, taking a different perspective when looking at their thoughts; and that lens can be an anti-racist one. Traditional mindfulness-based wellness practices have strong themes of social justice. As Dr. Chris Goto-Jones wrote, "Mindfulness is not a magical fix for this situation [racism \& bigotry], although the cultivation of mindfulness can certainly support us as we strive to respond compassionately, effectively, and skilfully... [but] the field of mindfulness is not free of its own forms of prejudice, discrimination, and injustice"(Goto-Jones, 2020). It is certainly is not free of discrimination, and when people of color share their experiences of injustice, members of the mindfulness community should listen and act accordingly regardless of if they share that experience. 
Mindfulness-based wellness spaces have also contributed more shame and trauma to people of color. Studios are often white-dominant; as such the climate of these spaces is interpreted very differently depending on the individual. To a white person, a space may feel calming, inviting, spiritual, a place of wellness. To a person of color, the same space may serve to make them feel like an outsider, someone who must be very careful to adhere to the unspoken rules of behavior and appearance. To walk in and not see anyone who looks like yourself, to feel overly conscious of how others in the space are perceiving you, does not make a space feel calming, inviting, or like a place to nurture wellness. Bruce notes that without intentional work to be anti-racist, these spaces are inherently racist.

"The yoga studio environment is encapsulated by systemic racism in America and the result of unacknowledged systemic racism enables the yoga studio environment to exist as a white, anti-black space... When I walk into a yoga studio, I am still perceived as a black woman. I still have to follow certain decorum such as wearing the yoga outfit, smiling, eye contact, being extra early for class. I do all of this so that I'm not removed from a space that wasn't made by or for me." (Bruce, 2019, p.12-13)

In, Black Buddhists and the Body: New Approaches to Socially Engaged Buddhism (Vesely-Flad, 2017), Black Buddhists critique and describe experiences of racism in their Socially Engaged Buddhist communities (communities that are primarily white, and affluent). Black practitioners consider how the oppression, suffering, and violence inflicted on Black people affects those that exist within white supremacist societies, and they directly challenge their white counterparts to consider the racism in their communities and selves. While Buddhist leaders have focused on ending suffering, it is less common for their perspectives to acknowledge how race, gender, and sexuality influence this suffering (Vesely-Flad, 2017). An example of microaggressions in Buddhist/meditative practices is the teaching of "No Self" (anattā or anātman), a core concept of Buddhism that there is no unchanging, permanent self, soul, or essence. Zenju Earthlyn Manuel, a woman of color and dharma heir, comments that teachings of "No Self" are often used to deny the suffering of racism; for Black people, these teachings feel diminishing of their historical and personal trauma (Manuel, 2015). 
"To describe "No Self" to people who have been historically dehumanized is often received as dismissing the weight of colonialism, genocide, slavery, and systemic racism that have been justified by interpretations of the body. Thus, black dharma teachers recognize that, to engage people of African descent, the teachings must be communicated in such a way that the reality of the body in society is acknowledged, and the truth of "No Self" is deconstructed and contemplated. (Vesely-Flad, 2017, p. 5)"

Other mindfulness practitioners and participants have called for the work of decolonizing mindfulness and oppressive systems of power (Street et al., 2020). They remind the mindfulness community that meditation is not enough, that intentional activism and decolonizing work are needed for change. Due to western mindfulness culture's focus on the individual rather than at the societal level, these changes will not come about naturally. For mindfulness-based wellness spaces to truly be accessible and welcoming to all, they must become actively anti-racist. Work must be done to prevent these spaces from causing Black, Indigenous, people of color (BIPOC) harm, only then can mindfulness-based wellness practices aid in healing racial trauma and be a tool for activism.

\section{Conclusion}

By critically examining how the United State's commodification of mindfulness-based wellness practices contributes to experiences of shame, exclusion, and appropriation in mindfulness-based wellness culture, communities can foster conversations on accessibility in wellness. Within this paper four major aspects of focus are identified: the commodification of mindfulness culture itself, and the corporate mindfulness practices, cultural appropriation, and racism that happen in response. Commodifying mindfulness-based wellness has resulted in inaccessible studios, equipment, and clothing due to price and focusing on specific target demographics (non-inclusive sizing) (Hall, 2015; Quilty et al., 2013). It has also resulted in the promotion of questionable gurus. Corporate mindfulness has looked at mindfulness-based wellness primarily as a tool to be utilized under capitalism (Walsh, 2018). As a result practices such as mindfulness meditation have been adapted to suit workplace environments in order to 
reduce stress. When mindfulness-based wellness practices are used only to manage negative feelings but not their root cause, MBW lacks long term, revolutionary power (Purser, 2019). Due to the historical origins of yoga and meditation in India, aspects of mindfulness-based wellness are appropriated by other cultural groups without a true understanding of their meaning or values (Bowers \& Cheer, 2017). Groups with cultural ties to meditation and yoga may feel ostracized, unacknowledged, and misrepresented within United States mindfulness-based wellness culture. The dominant demographic for yoga is upper-middle-class, white women (Park et al., 2015). Many yoga studios as a result do not maintain the same comforting, safe, and healing atmosphere for BIPOC (Bruce, 2019). For studios to be welcoming to BIPOC, international anit-racist work must be accomplished.

As stated above, reconciliation is needed between mindfulness teachings, practitioners, and participants of all backgrounds for mindfulness-based wellness practices and culture to be accessible and welcoming to all. A variety of diverse issues are discussed in this paper, and there is no perfect fit solution to address all of them. However, a strong approach would be to aggregate multiple suggestions, as each concern requires a unique approach. Bruce offers one solution in her creation of "stages of wokeness", based off of bell hooks's "healing maps" (Bruce, 2019). She describes this solution as a

"racial practice addressing the grief associated with arriving in our racialized bodies, the grief that comes when the veil of inequities related to race are revealed; and they are useful for black, white, and multicultural individuals. It begins with an initial phase of obliviousness to race, followed by a period of fragility when awareness is awakened. Following the first two phases of obliviousness and fragility we reach our desired, conversational phase (Bruce, 2019, p.9).

This approach is adaptable to discuss not only the influence of race in mindfulness-based wellness culture, but also other physical characteristics, culture, and class. 
Another powerful solution to the concerns addressed in this paper is ownership. When studios and businesses belong to people of color, there is a power shift away from white people. After feeling excluded and deprived of her spiritual heritage within U.S. mindfulness-based wellness culture, Lakshmi Nair founded the first People of Color yoga cooperative in the United States. Nair speaks of her decision to found Satya Yoga Cooperative as a result of the trauma she experienced within U.S. yoga culture, "I deliberately chose to go the cooperative route to liberate myself and all of our members from being at the whim of a yoga world that is largely modeled in the image of the neo-colonial economic paradigm that was built upon our exclusion, oppression, and the extraction of our cultural and material resources as people of color" (Nair, 2019, p. 38). Giving patronage, economical support, and social support to small, multicultural businesses goes a long way in disrupting the racism, cultural appropriation, commodification, and corporate control in mindfulness-based wellness culture. Empowering people to advocate for change in their own communities by sharing experiences (positive and negative) in mindfulness-based wellness begins with supportive relationships and open mindedness.

Lastly, meditation itself can support activism and intentional change. Meditation can be used to examine how each person perpetuates injustice by looking inward at their privilege, biases, and stereotypes (Cohen, 2020). Mindfulness meditation challenges a person to turn inward and investigate their thoughts, especially the ones that make them feel uncomfortable or shameful. This allows an individual to identify where they personally need to put in work.

The goal of this thesis is to uplift traditionally marginalized voices in an effort to make mindfulness-based wellness practices and spaces more inclusive. It is important to examine how the United State's commodification of mindfulness-based wellness practices contributes to experiences of shame, exclusion, and appropriation in wellness culture. There are many changes to be made in U.S. wellness culture for the realities of yoga and meditation to match their intentions of nurturing goodness and minimizing harm. While large-scale change may be 
daunting and a long way off, each of us can make a meaningful difference starting in our community.

Every day may we be mindful to work towards a better, more equitable wellness culture. Mindful to decolonize our practices by respecting their cultural roots by taking time to learn ancestral teachings. Mindful to decenter white narratives by actively listening to people of color, their concerns and critiques, and acting accordingly. Mindful to debrand our perceptions of yoga and meditation, their benefits are not dependent on having consumed/purchased the right things. Mindful to realign our intentions and ask ourselves daily, "what values are being nurtured in our practice?" May compassion and social justice be cornerstones of your practice. 


\section{References}

Atkinson, N. L., \& Permuth-Levine, R. (2009). Benefits, barriers, and cues to action of yoga practice: A focus group approach. American Journal of Health Behavior, 33(1), 3-15.

Abercrombie, P. D., Zamora, A., \& Korn, A. P. (2007). Lessons learned: Providing a mindfulness-based stress reduction program for low-income multiethnic women with abnormal pap smears. Holistic Nursing Practice, 21(1), 26-34.

Athleta. (n.d.). Our Core Values | B Corp. Retrieved February 6, 2021, from https://athleta.gap.com/browse/info.do?cid=1074427\&mlink=55287,15864962,Footer_O $\underline{\text { urValues\&clink }=15864962}$

Bialik, K., \& Fry, R. (2019, February 14). Millennial life: How young adulthood today compares with prior generations. Pew Research Center's Social \& Demographic Trends Project. https://www.pewsocialtrends.org/essay/millennial-life-how-young-adulthood-today-comp $\underline{\text { ares-with-prior-generations/ }}$

Blum, H. A. (2014). Mindfulness equity and Western Buddhism: Reaching people of low socioeconomic status and people of color. International Journal of Dharma Studies, 2(1), 10. https://doi.org/10.1186/s40613-014-0010-0

Bondy, Dianne. 2014. "Confessions of a Fat, Black Yoga Teacher." In Yoga and Body Image: 25 Personal Stories About Beauty, Bravery, and Loving Your Body, edited by Melanie Klein and Anna Guest-Jelley, 73-82. Minnesota: Llewellyn Publications.

Bowers, H., \& Cheer, J. M. (2017). Yoga tourism: Commodification and western embracement of eastern spiritual practice. Tourism Management Perspectives, 24, 208-216. https://doi.org/10.1016/j.tmp.2017.07.013

Buddhist Teachings on Mindfulness Meditation. (2017) Lion's Roar. Retrieved November 20, 2020, from https://www.lionsroar.com/buddhist-teachings-on-mindfulness-meditation/ Brief History of Qigong. (n.d.). Institute of Qigong \& Integrative Medicine. Retrieved November 20, 2020, from https://www.iqim.org/about/history-of-qigong/ 
Bränström, R., Duncan, L. G., \& Moskowitz, J. T. (2011). The association between dispositional mindfulness, psychological well-being, and perceived health in a Swedish population-based sample. British Journal of Health Psychology, 16(2), 300-316.

\section{https://doi.org/10.1348/135910710X501683}

Bruce, R. D. (2019). White Supremacist Yoga: A Black Feminist Perspective on Cultural Appropriation, Systemic. 16.

Chu, L.-C. (2010). The benefits of meditation vis-à-vis emotional intelligence, perceived stress and negative mental health. Stress and Health, 26(2), 169-180. https://doi.org/10.1002/smi.1289

Cohen, S. (2020). Using Meditation to Explore Privilege and Anti-Racism. Mindful Leader. Retrieved January 12, 2021, from https://www.mindfulleader.org/blog/42596-using-meditation-to-explore-privilege

Creswell, D., \& Khoury, B. (2019, October 30). Mindfulness meditation: A research-proven way to reduce stress. Https://Www.Apa.Org. https://www.apa.org/topics/mindfulness/meditation

Curious About the Origin and History of Yoga? Here's the CliffNotes Version. (2019, May 23). YogiApproved $^{T M}$. https://www.yogiapproved.com/om/origin-of-yoga-history-of-yoga/

Danis, L. (2018, September 14). How LGBTQ yoga can heal a community. The Establishment. https://theestablishment.co/how-lgbtq-yoga-can-heal-a-community/

Delaney, B. (2017, September 17). The yoga industry is booming - but does it make you a better person? The Guardian.

https://www.theguardian.com/lifeandstyle/2017/sep/17/yoga-better-person-lifestyle-exerc ise

Dutton, M. A., Bermudez, D., Matás, A., Majid, H., \& Myers, N. L. (2013). Mindfulness-based stress reduction for low-income, predominantly African American women with PTSD and 
a history of intimate partner violence. Cognitive and Behavioral Practice, 20(1), 23-32. https://doi.org/10.1016/j.cbpra.2011.08.003

Farrell, M. (2009, September 3). Bikram Yoga's New Twists. Forbes. Retrieved February 4, 2021, from https://www.forbes.com/forbes/2009/0921/entrepreneurs-franchising-bikram-yoga-new-t wists.html

Gregoire, C. (2013, December 16). How The Yoga Industry Lost (And Found) Its Soul Along The Way To Reinventing Spirituality In America. HuffPost. https://www.huffpost.com/entry/how-the-yoga-industry-los n_4441767

Goldstein, J. (2007). Here, Now, Aware: The Power of Mindfulness - Lion's Roar. Retrieved December 3, 2020, from https://www.lionsroar.com/buddhist-teachings-on-mindfulness/

Godwin, R. (2017, February 18). "He said he could do what he wanted": The scandal that rocked Bikram yoga. The Guardian.

https://www.theguardian.com/lifeandstyle/2017/feb/18/bikram-hot-yoga-scandal-choudhu ry-what-he-wanted

Goto-Jones, C. (2020, June 6). Mindfulness and racism in the pandemic. MENTALPRAXIS. http://www.mentalpraxis.com/4/post/2020/06/mindfulness-and-racism-in-the-pandemic.ht $\underline{\mathrm{ml}}$

Grossman, P., Niemann, L., Schmidt, S., \& Walach, H. (2004). Mindfulness-based stress reduction and health benefits: A meta-analysis. Journal of Psychosomatic Research, 57(1), 35-43. https://doi.org/10.1016/S0022-3999(03)00573-7

Hall. (2015, January 22). Here's why lululemon is charging $\$ 108$ for meditation beads. HuffPost. https://www.huffpost.com/entry/heres-why-lululemon-is-charging-108-for-meditation-bea ds $n \quad 6464434$

Hinduism vs Buddhism-3 Major Similarities and 4 Major Differences. Asia Highlights. Retrieved November 17, 2020, from https://www.asiahighlights.com/india/hinduism-vs-buddhism 
Keosaian, J. E., Lemaster, C. M., Dresner, D., Godersky, M. E., Paris, R., Sherman, K. J., \& Saper, R. B. (2016). "We're all in this together": A qualitative study of predominantly low income minority participants in a yoga trial for chronic low back pain. Complementary Therapies in Medicine, 24, 34-39. https://doi.org/10.1016/j.ctim.2015.11.007

Kristensen, M. L. (2018). Mindfulness and resonance in an era of acceleration: A critical inquiry. Journal of Management, Spirituality \& Religion, 15(2), 178-195. https://doi.org/10.1080/14766086.2017.1418413

Kumar, V., Jagannathan, A., Philip, M., Thulasi, A., Angadi, P., \& Raghuram, N. (2016). Role of yoga for patients with type II diabetes mellitus: A systematic review and meta-analysis. Complementary Therapies in Medicine, 25, 104-112. https://doi.org/10.1016/j.ctim.2016.02.001

Magee, R. (2015, May 14). How Mindfulness Can Defeat Racial Bias. Greater Good. https://greatergood.berkeley.edu/article/item/how mindfulness can_defeat racial_bias

Mark, J. (2020, June 9). The Vedas. Ancient History Encyclopedia. https://www.ancient.eu/The Vedas/

Manuel, Z. E. (2015). The Way of Tenderness: Awakening through Race, Sexuality, and Gender. Simon and Schuster.

Miller, A. L. (2016). Eating the other yogi: Kathryn Budig, the yoga industrial complex, and the appropriation of body positivity. Race and Yoga, 1(1), 1-24. Retrieved from https://escholarship.org/uc/item/2t4362b9

Mills, D. (2019, June 4). Hot Yoga: Is It Super-Heated Exercise or a Health Danger? Healthline. https://www.healthline.com/health-news/hot-yoga-booming-but-it-may-be-bad-for-you-05 1515 
Nair, L. (2019). When Even Spirit Has No Place to Call Home: Cultural Appropriation, Microaggressions, and Structural Racism in the Yoga Workplace. Race and Yoga, 4(1). Retrieved from https://escholarship.org/uc/item/8mn5k1m1

Neale, M. (2011). McMindfulness and frozen yoga: Rediscovering the essential teachings of ethics and wisdom. Dr. Miles Neale website.

O'Brien, Barbara. (2020, August 25). The Eightfold Path: The Way to Enlightenment in Buddhism. Learn Religions. Retrieved from https://www.learnreligions.com/the-eightfold-path-450067

Otorkpa, D. (2019, August 1). World Health Organization(WHO) Definition Of Health. Public Health.

https://www.publichealth.com.ng/world-health-organizationwho-definition-of-health/

Park, C. L., Braun, T., \& Siegel, T. (2015). Who practices yoga? A systematic review of demographic, health-related, and psychosocial factors associated with yoga practice. Journal of Behavioral Medicine, 38(3), 460-471. https://doi.org/10.1007/s10865-015-9618-5

Purser, R. (2019). McMindfulness: How mindfulness became the new capitalist spirituality. Watkins Media Limited.

Purser, R. E. (2018). Critical perspectives on corporate mindfulness. Journal of Management, Spirituality \& Religion, 15(2), 105-108. https://doi.org/10.1080/14766086.2018.1438038

Purser, R., \& Loy, D. (2013, August 31). Beyond McMindfulness | HuffPost. https://www.huffpost.com/entry/beyond-mcmindfulness_b_3519289

Ray, I. B., Menezes, A. R., Malur, P., Hiltbold, A. E., Reilly, J. P., \& Lavie, C. J. (2014). Meditation and Coronary Heart Disease: A Review of the Current Clinical Evidence. 14(4), 8. 
Roth, B., \& Robbins, D. (2004). Mindfulness-based stress reduction and health-related quality of life: Findings from a bilingual inner-city patient population. Psychosomatic Medicine, 66(1), 113-123. https://doi.org/10.1097/01.PSY.0000097337.00754.09

Rosenfeld, J. (2016, January 12). What If Yoga Weren’t So Expensive? The Atlantic. https://www.theatlantic.com/business/archive/2016/01/yoga-expensive-affordable/42354 $\underline{9 /}$

Saper, R. B., Lemaster, C., Delitto, A., Sherman, K. J., Herman, P. M., Sadikova, E., Stevans, J., Keosaian, J. E., Cerrada, C. J., Femia, A. L., Roseen, E. J., Gardiner, P., Gergen Barnett, K., Faulkner, C., \& Weinberg, J. (2017). Yoga, Physical Therapy, or Education for Chronic Low Back Pain. Annals of Internal Medicine, 167(2), 85-94. https://doi.org/10.7326/M16-2579

Segran, E. (2015, July 17). What's With All The Yoga Pants? Fast Company. https://www.fastcompany.com/3048094/whats-with-all-the-yoga-pants

Schreiner, I., \& Malcolm, J. P. (2008). The benefits of mindfulness meditation: Changes in emotional states of depression, anxiety, and stress. Behaviour Change, 156-168. https://doi.org/10.1375/bech.25.3.156

Scherer, B., \& Waistell, J. (2018). Incorporating mindfulness: Questioning capitalism. Journal of Management, Spirituality \& Religion, 15(2), 123-140. https://doi.org/10.1080/14766086.2017.1375424

Shapiro, S., \& Walsh, R. (2003). An analysis of recent meditation research and suggestions for future directions. The Humanistic Psychologist, 31(2-3), 86-114. https://doi.org/10.1080/08873267.2003.9986927

Shapiro, S., Jazaieri, H., \& Sousa, S. (2016). Meditation and Positive Psychology. https://doi.org/10.1093/oxfordhb/9780199396511.013.50 
Smith, S., \& Atencio, M. (2017). "Yoga is yoga. Yoga is everywhere. You either practice or you don't": A qualitative examination of yoga social dynamics. Sport in Society, 20(9), 1167-1184. https://doi.org/10.1080/17430437.2016.1269082

Spadola, C. E., Rottapel, R., Khandpur, N., Kontos, E., Bertisch, S. M., Johnson, D. A., Quante, M., Khalsa, S. B. S., Saper, R. B., \& Redline, S. (2017). Enhancing yoga participation: A qualitative investigation of barriers and facilitators to yoga among predominantly racial/ethnic minority, low-income adults. Complementary Therapies in Clinical Practice, 29, 97-104. https://doi.org/10.1016/j.ctcp.2017.09.001

Street, Z. T. T. 1255 23rd, Washington, N. S. 350, \& Dc 20037638-1144899-4301. (2020, October 31). PERSPECTIVES—Defunding Mindfulness: While We Sit on Our Cushions, Systemic Racism Runs Rampant. ZERO TO THREE. https://www.zerotothree.org/resources/3715-perspectives-defunding-mindfulness-whilewe-sit-on-our-cushions-systemic-racism-runs-rampant

Streeter, C. C., Gerbarg, P. L., Saper, R. B., Ciraulo, D. A., \& Brown, R. P. (2012). Effects of yoga on the autonomic nervous system, gamma-aminobutyric-acid, and allostasis in epilepsy, depression, and post-traumatic stress disorder. Medical Hypotheses, 78(5), 571-579. https://doi.org/10.1016/j.mehy.2012.01.021

Quilty, M. T., Saper, R. B., Goldstein, R., \& Khalsa, S. B. S. (2013). Yoga in the Real World: Perceptions, Motivators, Barriers, and Patterns of Use. Global Advances in Health and Medicine, 2(1), 44-49. https://doi.org/10.7453/gahmj.2013.2.1.008

Vesely-Flad, R. (2017). Black Buddhists and the Body: New Approaches to Socially Engaged Buddhism. Religions, 8(11), 239. http://dx.doi.org.proxy.lib.pdx.edu/10.3390/rel8110239

Walsh, Z. (2018). Mindfulness under neoliberal governmentality: Critiquing the operation of biopower in corporate mindfulness and constructing queer alternatives. Journal of Management, Spirituality \& Religion, 15(2), 109-122. https://doi.org/10.1080/14766086.2017.1423239 
Webb, J. B., Rogers, C. B., \& Thomas, E. V. (2020). Realizing yoga's all-access pass: A social justice critique of westernized yoga and inclusive embodiment. Eating Disorders, 28(4), 349-375. https://doi.org/10.1080/10640266.2020.1712636 